\title{
PENGOLAHAN SINYAL GEOMAGNETIK DI REGIONAL LOMBOK DENGAN METODE FRAKTAL
}

\section{Geomagnetic Signal Processing in the Lombok Region using Fractal Method}

\author{
Bulkis Kanata $^{1,2}$, Teti Zubaidah ${ }^{1,2}$, I Gusti Ayu Kusdiah ${ }^{1}$ \\ 1) Jurusan Teknik Elektro, Universitas Mataram. Jl. Majapahit 62, Mataram, 83125 Lombok, Indonesia \\ 2) PUI Geomagnetik, Jurusan Teknik Elektro, Universitas Mataram. J.. Majapahit 62, Mataram, Indonesia \\ Email: uqikanata@unram.ac.id; tetizubaidah@unram.ac.id; igakusdiah@gmail.com
}

\section{ABSTRAK}

Pulau Lombok merupakan salah satu pulau di Indonesia dengan tingkat aktivitas kegempaan yang tinggi, karena Indonesia sendiri berada pada cincin api. Gunung Rinjani merupakan gunung berapi aktif yang dapat dikaitkan dengan kegempaan di pulau tersebut yang dapat mempengaruhi perubahan medan geomagnetik dalam hal ini bisa menimbulkan anomali geomagnetik. Berdasarkan hal tersebut maka dilakukan penelitian terhadap dimensi fraktal sinyal geomagnetik di wilayah Lombok menggunakan data observatorium Kupang (KPG), Kakadu (KDU) dan Guam (GUA) untuk menentukan anomali yang dapat diduga sebagai prekursor gempa bumi. Dimensi fraktal pada gempa merusak terlihat pada rentang waktu 12-43 hari sebelum kejadian gempa dan 5-46 hari untuk gempa kecil dan besar dimensi fraktal linear terhadap jarak gempa ke observatorium.

Kata Kunci: dimensi fraktal, geomagnetic, gempa, prekursor

\section{ABSTRACT}

Lombok Island is one of the islands in Indonesia with a high level of seismic activity, because Indonesia itself is in the ring of fire. Mount Rinjani is an active volcano that can be associated with seismicity on the island which can affect changes in geomagnetic fields in this case can cause geomagnetic anomalies. Based on this, a study of the fractal dimensions of geomagnetic signals in the Lombok region used data of Kupang Observatory (KPG), Kakadu (KDU) and Guam (GUA) to determine anomalies that could be suspected as earthquake precursors. The fractal dimension of a destructive earthquake is seen in the range of 12-43 days before the earthquake event and 5-46 days for small and large earthquake linear fractal dimensions with respect to the distance of the earthquake to the observatory.

Key words: fractal dimension, geomagnetic, earthquake, precursor

\section{PENDAHULUAN}

Indonesia merupakan salah satu negara dengan tingkat aktivitas kegempaan yang tinggi. Hal ini disebabkan karena posisi Indonesia terletak pada pertemuan tiga lempeng tektonik utama di dunia, yakni lempeng Eurasia, lempeng Indo-Australia, dan lempeng Pasifik. Selain itu Indonesia berada pada jalur ring of fire dimana Indonesia memiliki jumlah gunung berapi paling banyak di dunia. Ring of fire atau yang dikenal dengan sebutan Cincin Api Pasifik merupakan daerah yang sering mengalami gempa bumi dan letusan gunung berapi. Di Indonesia tercatat memiliki 130 gunung berapi, 17 diantaranya masih aktif [1]. Salah satu wilayah di Indonesia yang memiliki gunung berapi yang masih aktif adalah pulau Lombok, yaitu Gunung Rinjani. Gunung Rinjani merupakan gunung kedua tertinggi di
Indonesia dengan ketinggian $3.726 \mathrm{~km}$ di atas permukaan laut. Menurut Pusat Vulkanologi dan Mitigasi Bencana Bandung menyatakan Gunung Rinjani di Kabupaten Lombok Timur, NTB, masih berstatus waspada [2].

Total kejadian gempa di Lombok dan sekitarnya dari tahun 1900 sampai 2014 adalah 2081 kejadian, yakni amplitudo gempa 4-4.9 SR terdapat 1709 kejadian, 5-5.9 SR terdapat 336 kejadian, dan 6-8 SR terdapat 36 kejadian. Gempa-gempa tersebut merupakan gempa-gempa dangkal (kedalaman < $40 \mathrm{~km}$ ) yang berpotensi menimbulkan bencana [3].

Menurut penelitian yang sudah dilakukan menyatakan bahwa kejadian gempa bumi ditandai dengan munculnya prekursor, yang dapat dilakukan penelitian untuk memprediksi kejadiannya, sehingga dapat 
mengurangi kerusakan dan kerugian yang ditimbulkan akibat gempa bumi [4].

Munculnya gempa bumi ditandai dengan adanya fenomena alam terlebih dahulu, namun munculnya fenomena alam tersebut baru diketahui setelah terjadi gempa bumi yang menimbulkan kerugian yang sangat besar, baik berupa harta benda maupun jiwa manusia [5].

Penelitian mengenai anomali medan elektromagnetik berkaitan dengan terjadinya gempa bumi. Untuk mengamati anomali pada variasi medan elektromagnetik dibutuhkan metode pengolahan sinyal yang dapat memisahkan antara gangguan yang berasal dari dalam bumi akibat adanya aktivitas seismik dengan gangguan yang timbul akibat aktivitas geomagnet yang berasal dari magnetosfer (badai magnet) dan dari badai matahari (variasi harian dan musiman). Salah satu wilayah di Indonesia yang memiliki gunung berapi yang masih aktif adalah pulau Lombok, yaitu Gunung Rinjani. Gunung Rinjani merupakan gunung kedua tertinggi di Indonesia dengan ketinggian $3.726 \mathrm{~km}$ di atas permukaan laut. Menurut Pusat Vulkanologi dan Mitigasi Bencana Bandung menyatakan Gunung Rinjani di Kabupaten Lombok Timur, NTB, masih berstatus waspada[2].

Tabel 1. Data Gempa Tahun 2013

\begin{tabular}{|c|c|c|c|c|c|c|c|c|c|}
\hline \multirow{2}{*}{ No. } & \multirow{2}{*}{$\begin{array}{l}\text { Kode } \\
\text { Gempa }\end{array}$} & \multicolumn{2}{|c|}{ Waktu } & \multirow{2}{*}{ Titik Koordinat } & \multirow{2}{*}{$\begin{array}{l}\text { Magnitud } \\
\text { o (SR) }\end{array}$} & \multirow{2}{*}{$\begin{array}{l}\text { Kedalaman } \\
\quad(\mathrm{Km})\end{array}$} & \multicolumn{3}{|c|}{$\begin{array}{c}\text { Jarak dari Pusat Gempa ke } \\
\text { Observatorium }(\mathrm{Km})\end{array}$} \\
\hline & & Tanggal & $\begin{array}{l}\text { PUKUL } \\
\text { (AM) }\end{array}$ & & & & KPG & KDU & GUA \\
\hline 1 & A & 02/04/2013 & $12: 33: 08$ & 8.30 LS ; 116.74 BT & 3.5 & 10 & 789 & 1791 & 3907 \\
\hline 2 & B & $22 / 06 / 2013$ & $05: 42: 37$ & 8.44 LS ; 116.04 BT & 5.2 & 16 & 860 & 1855 & 3945 \\
\hline 3 & $\mathrm{C}$ & $01 / 07 / 2013$ & 03:38:32 & 8.30 LS ; 116.04 BT & 3.2 & 10 & 864 & 1859 & 3914 \\
\hline 4 & $D$ & $24 / 09 / 2013$ & 01:33:41 & 8.81 LS ; 115.89 BT & 3.1 & 10 & 868 & 1866 & 3998 \\
\hline 5 & $E$ & $15 / 12 / 2013$ & 02:19:37 & 8.31 LS ; 116.06 BT & 3.9 & 10 & 861 & 1858 & 3949 \\
\hline
\end{tabular}

\section{PENGAMBILAN DAN PENGOLAHAN SINYAL}

Data geomagnetik yang digunakan adalah komponen Horizontal (H), D (Deklinasi) dan Z (Vertikal) yang tercatat dalam rentang waktu 6 jam (pukul 00:00-06:00 AM), yang bersumber dari tiga obsevatorium/stasiun yakni stasiun Kupang (KPG) milik Lembaga Antariksa dan Penerbangan Nasional (LAPAN), serta dua observatorium yang telah terintegrasi dengan jaringan INTERMAGNET yaitu Kakadu (KDU) di Australia dan Guam (GUA) di Samudra Pasifik.

Tabel 2. Posisi Geografis Observatorium

\begin{tabular}{|c|l|c|c|}
\hline \multirow{2}{*}{$\begin{array}{c}\text { Observator } \\
\text { ium }\end{array}$} & \multirow{2}{*}{ Negara } & \multicolumn{2}{|c|}{ Geografis } \\
\cline { 3 - 4 } & & Latitude & Longitude \\
\hline KPG & Indonesia & $10.17^{\circ} \mathrm{LS}$ & $123.59^{\circ} \mathrm{BT}$ \\
\hline GUA & Amerika & $13.50^{\circ} \mathrm{LU}$ & $144.8^{\circ} \mathrm{BT}$ \\
\hline KDU & Australia & $12.69^{\circ} \mathrm{LS}$ & $132.47^{\circ} \mathrm{BT}$ \\
\hline
\end{tabular}

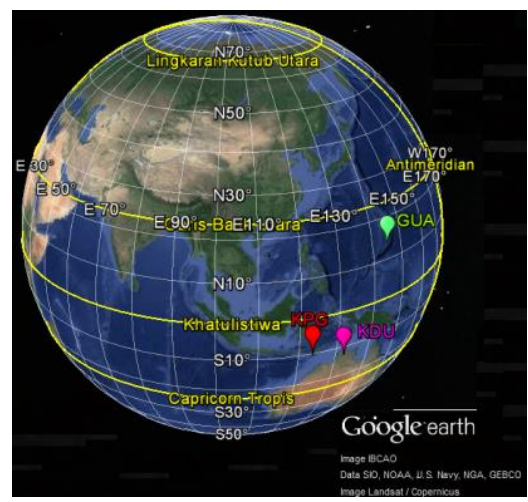

Gambar 1. Letak Geografis Observatorium

\section{METODE PENGOLAHAN SINYAL}

Pengolahan data geomagnetik dengan metode fraktal menggunakan data observatorium yang berdekatan dengan pusat gempa. Langkah-langkah proses fraktal sebagai berikut:

1. Menentukan sinyal ULF dengan mengubah nilai medan geomagnetik dari domain waktu ke domain frekuensi (FFT) [6]. 
2. Menghitung power spectral density (psd) untuk respon frekuensi masing-masing dengan menggunakan persamaan (1) [6]:

$$
s_{i}(f)=\frac{\left\lceil B_{i}(f)\right]^{2}}{\Delta f}
$$

Keterangan:

$S_{i}(f)=$ nilai psd untuk tiap komponen.

$B_{i}(\mathrm{f})=$ nilai maksimum dari sinyal ULF untuk tiap komponen.

$\Delta f=$ frekuensi atas - frekuensi bawah $(\mathrm{Hz})$.

3. Menghitung nilai beta $(\beta)$ yaitu gradient log psd terhadap log frekuensi.

4. Menghitung dimensi fraktal sebagaimana persamaan (2):

$$
D_{0}=(5-\beta) / 2
$$

\section{HASIL DAN PEMBAHASAN}

\section{A. Dimensi Fraktal Komponen $\boldsymbol{H}$}

\section{A.1. Gempa Merusak (Gempa Kode B)}

Pada Gambar 2 menunjukan adanya anomali geomagnetik pada DOY 161 (12 hari sebelum kejadian gempa) dengan nilai sigma $\mathrm{Kp}=18$ yang menunjukkan nilai dimensi fraktal pada observatorium KPG, KDU dan GUA masing-masing 2.17, 2.12 dan 1.20.

\section{A.2. Gempa Kecil (Gempa Kode A, C, D dan E)}

Gempa Kode A terjadi pada DOY 94 yang terjadi pada tanggal 4 April 2013, pukul 00:33:08 waktu lokal, jarak gempa kode A dari observatorium KPG, KDU, dan GUA masingmasing $789 \mathrm{~km}, 1791 \mathrm{~km}$, dan $3907 \mathrm{~km}$, dengan magnitudo $3.5 \mathrm{SR}$, dan kedalaman 10 km. Pada Gambar 3 menunjukkan adanya anomali pada DOY 63 (31 hari sebelum gempa) dengan nilai sigma $\mathrm{Kp}=8.7$ dengan nilai dimensi fraktal tidak ada data untuk observatorium KPG, 1.88 untuk observatorium KDU, dan 1.48 untuk observatorium GUA.

Gempa dengan kode C terjadi pada DOY 182 yang terjadi pada tanggal 1 Juli 2013, pukul 03:38:32 waktu lokal, jarak gempa kode C dari observatorium KPG, KDU, dan GUA masing-masing $864 \mathrm{~km}, 1859 \mathrm{~km}$ dan 3941 $\mathrm{km}$ dengan magnitudo $3.2 \mathrm{SR}$, dan kedalaman $10 \mathrm{~km}$. Dari Gambar 2, tidak terlihat adanya anomali geomagnetik yang dapat dijadikan prekursor gempa.

Gempa dengan kode D terjadi pada DOY 267 yang terjadi pada tanggal 24 September 2013, pukul 01:33:41 waktu lokal, jarak gempa kode $D$ dari observatorium KPG, KDU dan GUA masing-masing $868 \mathrm{~km}, 1866 \mathrm{~km}$ dan $3998 \mathrm{~km}$, dengan magnitudo $3.1 \mathrm{SR}$ dan kedalaman $10 \mathrm{~km}$. Dari Gambar 2, menunjukkan adanya anomali pada DOY 236 (31 hari sebelum gempa) dengan nilai sigma $\mathrm{Kp}=14$, pada gambar menunjukkan nilai dimensi fraktal untuk observatorium KPG, KDU dan GUA masing-masing 1.91, 1.67 dan 1.38 .

Gempa dengan kode E terjadi pada DOY 349 yang terjadi pada tanggal 15 Desember 2013, pukul 02:19:37 waktu lokal, jarak gempa kode $\mathrm{E}$ dari observatorium KPG, KDU dan GUA masing-masing $861 \mathrm{~km}, 1858 \mathrm{~km}$, dan $3949 \mathrm{~km}$, dengan magnitudo $3.9 \mathrm{SR}$, dan kedalaman $10 \mathrm{~km}$. Pada Gambar 2 menunjukkan adanya anomali pada DOY 347 ( 2 hari sebelum gempa) dengan nilai sigma $\mathrm{Kp}=6$, pada gambar nilai dimensi fraktal untuk observatorium KPG, KDU dan GUA masing-masing 1.90, 1.82 dan 1.91.

\section{A.3. Anomali non prekursor gempa}

Anomali dapat terjadi bukan hanya sebagai prekursor gempa, namun dapat juga disebabkan oleh badai matahari. Seperti yang terjadi pada DOY 76, 248 dan 342 dengan nilai sigma $\mathrm{Kp}>20$.

\section{B. Dimensi Fraktal Komponen H}

\section{B.1. Gempa Merusak (Gempa Kode B)}

Pada Gambar 3 menunjukan adanya anomali geomagnetik pada DOY 130 (43 hari sebelum terjadi gempa) dengan nilai sigma $\mathrm{Kp}$ = 7 yang menunjukkan nilai dimensi fraktal untuk observatorium KPG, KDU dan GUA masing-masing 1.951 .49 dan 1.59.

\section{B.2. Gempa Kecil (Gempa Kode A, C, D dan \\ E)}

Gempa Kode A terjadi pada DOY 94. Pada Gambar 3 menunjukkan adanya anomali pada DOY 63 (31 hari sebelum gempa) dengan nilai sigma $\mathrm{Kp}=8.7$ yang menunjukkan tidak ada data dimensi fraktal untuk observatorium KPG, 1.88 untuk observatorium KDU, dan 1.48 untuk observatorium GUA.

Gempa dengan kode $\mathrm{C}$ terjadi pada DOY 182. Gambar 3 tidak terlihat adanya anomali geomagnetik yang dapat dijadikan prekursor gempa.

Gempa dengan kode $\mathrm{D}$ terjadi pada DOY 267. Pada Gambar 3 menunjukkan adanya anomali pada DOY 221 (46 hari sebelum gempa) dengan nilai sigma $\mathrm{Kp}=13$ dengan nilai dimensi fraktal untuk observatorium KPG, 
KDU dan GUA masing-masing 1.90, 1.63 dan 1.58 .

Gempa dengan kode E terjadi pada DOY 349. Pada Gambar 3 menunjukkan adanya anomali pada DOY 344 (5 hari sebelum gempa) dengan nilai sigma $\mathrm{Kp}=7.3$, pada gambar menunjukkan nilai dimensi fraktal untuk observatorium KPG, KDU dan GUA masing-masing 2.45, 1.53 dan 1.43.

\section{B.3. Anomali non-Prekursor Gempa}

Anomali dapat terjadi bukan hanya sebagai prekursor gempa, namun dapat juga disebabkan oleh badai matahari. Seperti yang terjadi pada DOY 342 dengan nilai sigma Kp $>20$.

\section{Dimensi Fraktal Komponen Z}

\section{C.1. Gempa Merusak (Gempa Kode B)}

Gempa Kode B terjadi pada DOY 174. Pada Gambar 4 menunjukan adanya anomali geomagnetik pada DOY 142 (32 hari sebelum gempa) dengan nilai sigma $\mathrm{Kp}=18.7$, pada gambar tersebut menunjukkan nilai dimensi fraktal untuk observatorium KPG, KDU dan GUA masing-masing 1.92, 1.74 dan 2.06.

C.2. Gempa Kecil (Gempa Kode A, C, D dan E)

Gempa Kode A terjadi pada DOY 94. Pada Gambar 4 menunjukkan adanya anomali pada DOY 77 (17 hari sebelum gempa) dengan nilai sigma $\quad K p=14$, pada gambar tersebut menunjukkan nilai dimensi fraktal untuk observatorium KPG, KDU dan GUA masingmasing 1.70, 2.02 dan 1.55.

Gempa dengan kode $\mathrm{C}$ terjadi pada DOY 182. Gambar 4 tidak terlihat adanya anomali geomagnetik yang dapat dijadikan prekursor gempa.

Gempa dengan kode $\mathrm{D}$ terjadi pada DOY 267. Pada Gambar 4 menunjukkan adanya anomali pada DOY 242 (25 hari sebelum gempa) dengan nilai sigma $\mathrm{Kp}=13$, pada gambar nilai dimensi fraktal tidak ada data untuk observatorium KPG, 2.33 untuk observatorium KDU, dan 1.50 untuk observatorium GUA.

Gempa dengan kode E terjadi pada DOY 349. Pada Gambar 4 menunjukkan adanya anomali pada DOY 344 ( 5 hari sebelum gempa) dengan nilai sigma $\mathrm{Kp}=7.3$, pada gambar nilai dimensi fraktal untuk observatorium KPG, KDU dan GUA masingmasing 2.01, 1.38 dan 1.61 .

C.3. Anomali non Prekursor Gempa

Anomali dapat terjadi bukan hanya sebagai prekursor gempa, namun dapat juga disebabkan oleh badai matahari. Seperti yang terjadi pada DOY 152, 153, 158, 179, dan 342 yang nilai sigma $\mathrm{Kp}>20$.

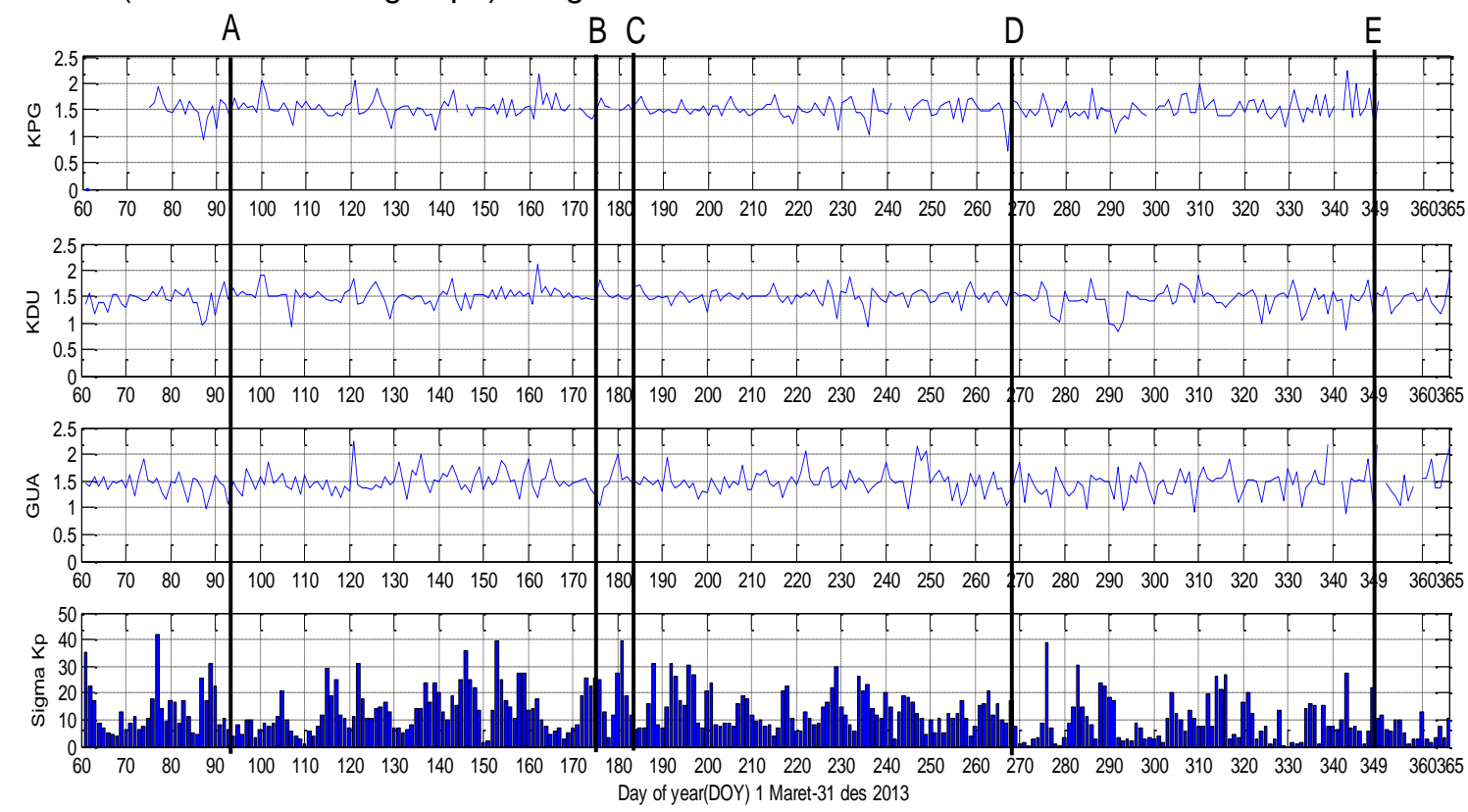

Gambar 2. Dimensi Fraktal Komponen H 
A

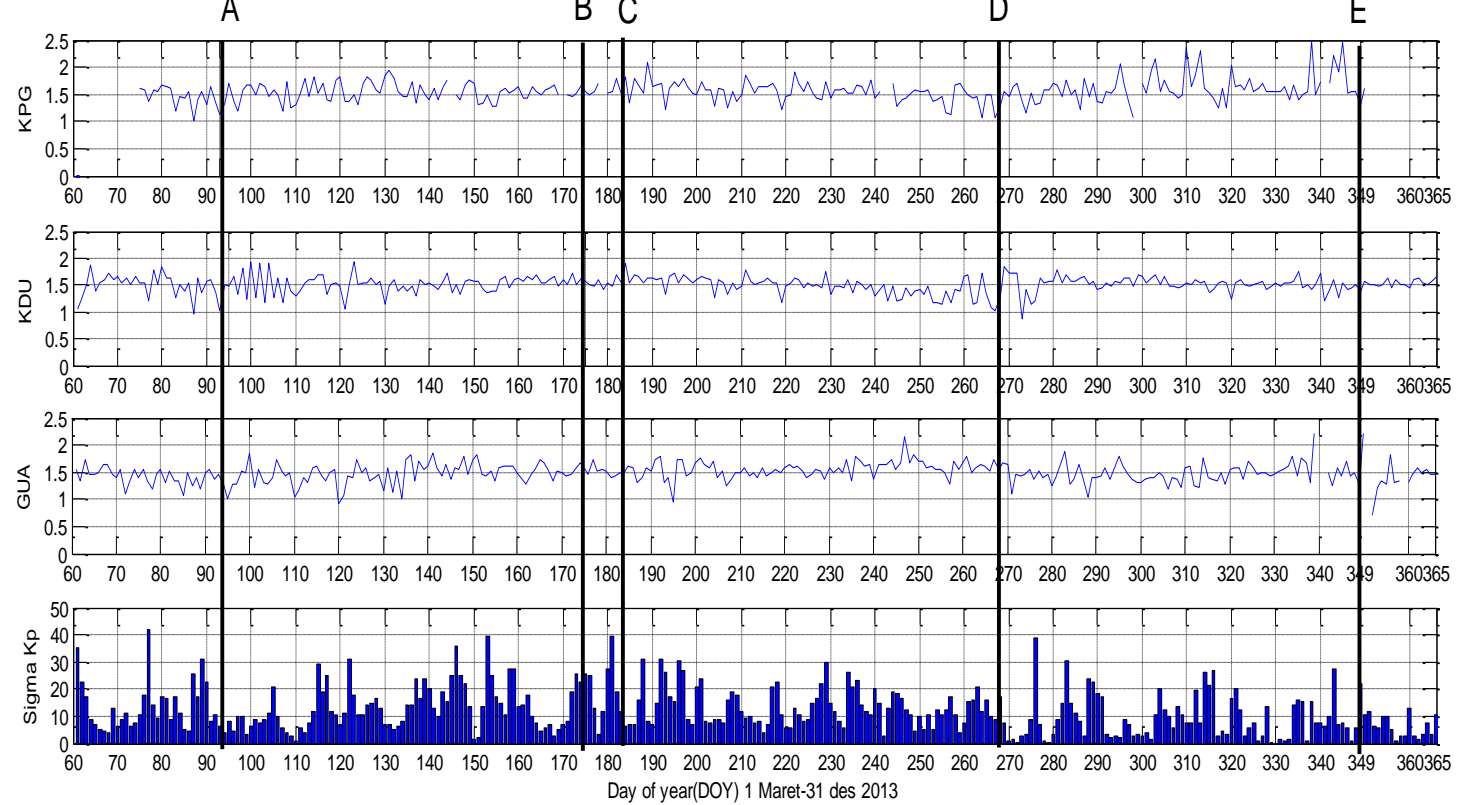

Gambar 3. Dimensi Fraktal Komponen D

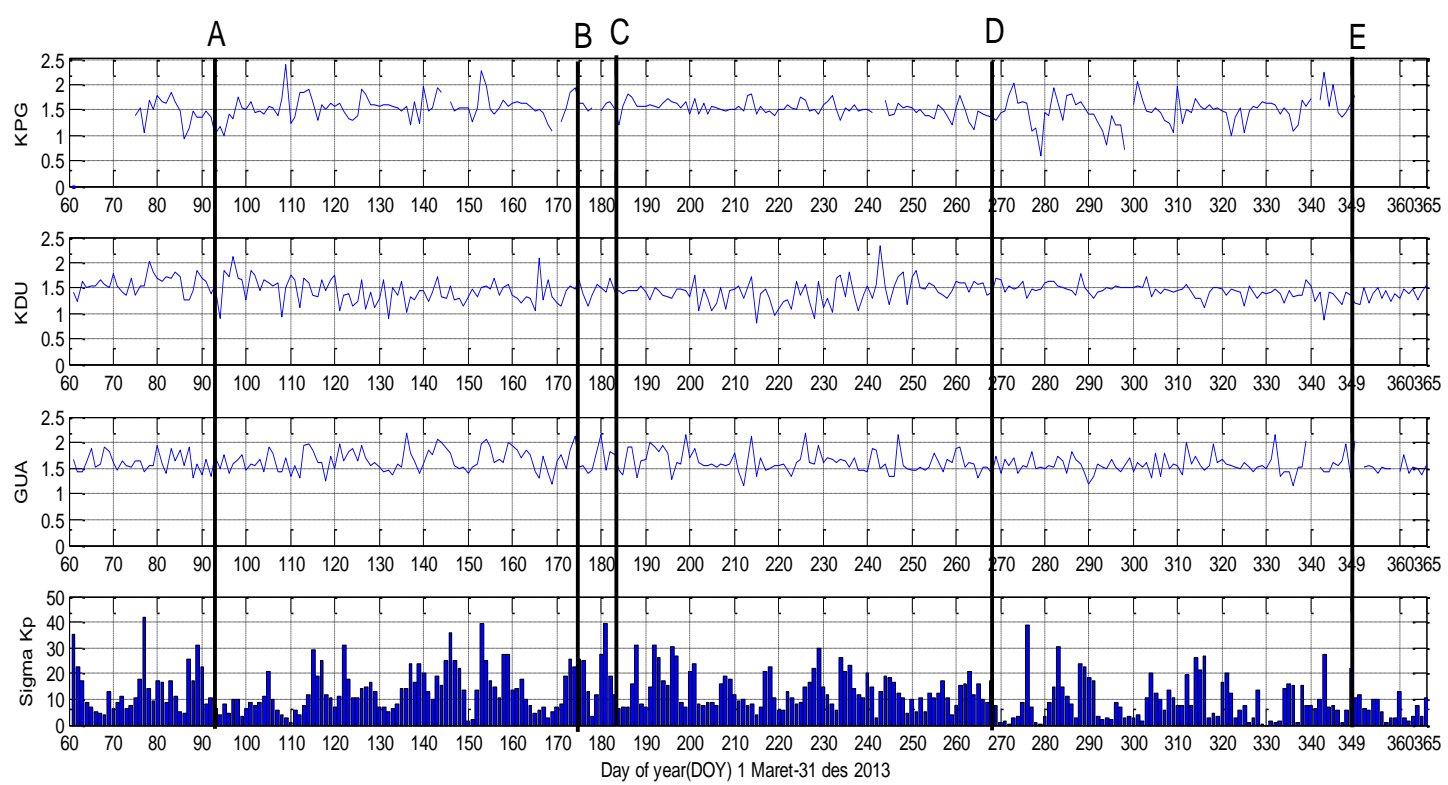

Gambar 4. Dimensi Fraktal Komponen Z

Anomali geomagnetik dalam hal ini dimensi fraktal untuk gempa merusak pada semua komponen terlihat pada rentang waktu 12-43 hari sebelum kejadian gempa. Sedangkan gempa kecil terlihat pada rentang waktu 5-46 hari sebelum kejadian gempa. Rata-rata dimensi fraktal untuk semua komponen pada gempa merusak yakni observatorium KPG, KDU dan GUA masingmasing sebesar 2.01; 1.78 dan 1.62. Ratarata dimensi fraktal untuk semua komponen pada gempa kecil yakni observatorium KPG,
KDU dan GUA masing-masing sebesar 2.03, 1.79 dan 1.55. Dari ketiga observatorium memperlihatkan bahwa besaran dimensi fraktal tertinggi berada pada data observatorium KPG, disusul dengan data observatorium KDU kemudian GUA. Dari urutan tersebut besar dimensi fraktal linear terhadap jarak gempa ke observatorium. Namun jika diperhatikan nilai rentang dimensi fraktal untuk gempa merusak dan gempa kecil hampir sama, namun kedalaman gempa pada 
gempa merusak lebih dalam yaitu $16 \mathrm{~km}$ sedangkan gempa kecil $10 \mathrm{~km}$.

\section{KESIMPULAN}

a. Anomali geomagnetik (dimensi fraktal) pada gempa merusak terlihat pada rentang waktu 12-43 hari sebelum kejadian gempa dan 5-46 hari untuk gempa kecil.

b. Pengolahan sinyal geomagnetik dengan metode fraktal yang dilakukan pada data tahun 2013, diperoleh rata-rata nilai dimensi fraktal untuk semua komponen pada tiap observatorium KPG, KDU dan GUA masing-masing sebesar 2.01, 1.78 dan 1.62 untuk gempa merusak, sedangkan gempa kecil masing-masing sebesar 2.03, 1.79 dan 1.55.

c. Besar dimensi fraktal linear terhadap jarak gempa dari observatorium.

\section{UCAPAN TERIMA KASIH}

Kami mengucapkan terima kasih kepada LAPAN atas kesediaan memberikan data geomagnetik dari stasiun KPG dan INTERMAGNET yang selalu menyediakan data geomagnetik online dengan standar tinggi yang memudahkan kami untuk mengaksesnya. MATLABß dengan nomor lisensi 863485 yang digunakan untuk pengolahan data serta Google Earth yang digunakan untuk plot posisi observatorium.

\section{DAFTAR PUSTAKA}

[1] Jiyo, "Kajian Hasil Uji Frekensi HF Pada Sirkit Komunikasi Radio di Lingkungan KOHANUDNAS", Berita Dirgantara Vol. 10, No. 4.LAPAN, 2009.

[2] B. Kanata, T. Zubaidah, B. Irmawati, C. Ramadhani, "Pengolahan Sinyal Geomagnetik sebagai Prekursor Gempa Bumi di Regional Jepang," Proceeding of Konferensi Nasional Sistem Informasi (KNSI), 2013, ISBN: 978602-17488-0-0.

[3] I. P. Kinasih, G. W. Wiriasto, B. Kanata, T. Zubaidah, "Lesser Sunda Island Earthquake Inter-Occurrence Times Distribution Modeling", International Journal of Technology, Vol. 3: 242-250, 2014.

[4] J. Maspupu, J, “Penentuan Hubungan Eksponen Spektral dan Dimensi Fraktal Sinyal ULF Geomagnet" , Proceeding Seminar Nasional Matematika dan Pendidikan Matematika Jurusan Pendidikan Matematika
FMIPA UNY, 2009, ISBN 978 - 979 - $16353-3-2$.

[5] N. A. Smirnova, I. V. Yakovitskaya, Russia. M. Hayakawa, T. Itoh, "Fractal Characteristics Of The Natural ULF Emissions In Relation To Geomagnetic Activity", IEEE 2005, ISBN : 07803-9374-0.

[6] B. Kanata, T. Zubaidah, C. Ramadhani, B. Irmawati, "Changes of The Geomagnetic Signals Linked to Tohoku Earthquake on March 11th 2011", International Journal of Technology, 5 (3), pp. 251-258, ISSN 20869614, 2014. 